\title{
A Community of Practice for Chinese NGOs
}

\author{
Reza Hasmath ${ }^{1}$ • Jennifer Y. J. Hsu ${ }^{2}$ (iD \\ Published online: 27 August 2020 \\ (C) Journal of Chinese Political Science/Association of Chinese Political Studies 2020
}

\begin{abstract}
A community of practice represents an important resource for the sharing of sectorspecific knowledge. Embracing a mature community of practice allows Chinese NGOs to forge networks to share best/worst practices, and foster common norms of conduct. This, in turn, offers a chance to increase the speed of professionalizing the sector, to the extent that there will be greater predictability in NGOs' activities. Predictability is important since it increases the state's trust of the NGO sector, and improves greater odds for soliciting external funding. Drawing upon original survey data elicited from over 100 NGOs, this article analyzes the organizational capacity for Chinese NGOs to cultivate a community of practice, and discusses the headwinds and challenges that will ensue.
\end{abstract}

Keywords NGOs · Community of practice $\cdot$ Knowledge sharing $\cdot$ Professionalization . China

\section{Introduction}

Chinese non-governmental organizations (NGOs) have numerically increased in the past three decades, particularly those focused on social service delivery [17]. This is partially due to the changing institutional environment and devolving state responsibilities in delivering social and welfare provisions [18]. This is characterized in the 12th Five Year Plan (FYP) (2011-2015) where the state articulated an explicit goal to outsource public goods and social services to non-state actors such as NGOs. The 12th FYP outlined a number of principles for the participation of non-state stakeholders involved in social service delivery. This notably included: (1) abiding by a multistakeholder governance mechanism to deliver social welfare provisions; (2)

Jennifer Y. J. Hsu

jenniferhsu@cantab.net

1 University of Alberta, Edmonton, Canada

2 University of New South Wales, Sydney, Australia 
strengthening the capacity and autonomy of local communities to provide services; and, (3) emphasizing the development of social organizations.

With the state actively encouraging Chinese NGOs to participate in social service delivery, we suggest that developing a community of practice has become an even more important mechanism for the sector to transmit knowledge and information (see Hsu and Hasmath [19] for background information). This article examines the organizational capacity for Chinese NGOs to cultivate a community of practice.

At the most basic level, a community of practice provides a mode to share sectorspecific knowledge with stakeholders and participants, and therefore, it is important for NGOs in China since it is a medium for individuals and organizations in the sector to learn and collaborate. As Sharkie [29] suggests, a community of practice represents shared practices built on a platform of trust. This is reinforced by studies by McDermott [24], Kaser and Miles [21] and Probst and Borzillo [27] who see networks amongst the key vehicles for knowledge sharing.

What makes our analysis timely - to discern whether Chinese NGOs have the organizational capacity to develop a community of practice - is the passing of China's first Charity Law which came into force in September 2016. While the Charity Law is generally seen as a way for the state to gain greater overt control over the sector (see e.g. [18] for a discussion on overt and tacit sanctioning of NGO activities), of particular analytical interest was Article 24 which allowed domestic NGOs for the first time to form a professional association. A professional association effectively provides an institutional framework for NGOs to overtly forge networks amongst each other, share best and worst practices, and work towards fostering common norms of conduct. Article 24 thus fostered a space for greater contact between Chinese NGOs and to increase the professionalization of the industry (due to this increased contact) to the extent that there will be greater predictability in their activities. The state wants Chinese NGOs' activities to be predictable since it increases the state's trust of the NGO sector; increases greater odds of soliciting funding from private foundations and the state; and finally, professionalization leads to a consistent higher standard of service delivery to recipients. In short, Article 24 provided a good mechanism, in principle, to birth a functioning community of practice.

Just prior to the Charity Law's enactment, we conducted an original survey with social and welfare-oriented NGOs across four cities - Shanghai, Nanjing, Chongqing and Kunming - looking at their organizational behaviour. These four cities provide an insight into the diverse landscape that characterize the Chinese NGO sector, including issues pertinent to specific locations, the type of resources available for professionalization, and the level of state involvement in the sector. We probed into Chinese NGOs potential for a 'professionalize project' (i.e. the act and process of professionalizing the sector; see Freidson [11]), and the extent that a community of practice was emerging amongst them. We specifically look at NGOs' staffing profile, the level of knowledge and expertise in the NGO's respective areas of operation, and relatedly, the prospect for individuals in NGOs and the organization-at-large to transmit best and worst practices to others in the sector. These are acknowledged seminal characteristics for analyzing the development of a 'professionalize project' and a community of practice $[15,31]$. In the following, we present our findings and discuss the potential for Chinese NGOs to grow a community of practice, and facilitate the professionalization of the sector. 


\section{Theoretical Background}

At the most basic level, a community of practice is based on a common practice outside the formal structure of an organization, and achieves coherence by combining three elements: (1) mutual engagement, (2) a joint enterprise, and (3) a shared repertoire. Mutuality emerges from interactions that occur by being engaged in the same action. The members of a community of practice have developed a common sense for what the community is about through a joint enterprise, and what its position is within a wider context. The shared "repertoire of a community of practice includes routines, words, tools, ways of doing things, stories, gestures, symbols, genres, actions, or concepts that the community has produced or adopted in the course of its existence, and which have become part of its practice" [33].

Within a community, knowledge can be easily communicated because of the shared perspective [6], and it can be seen as a matter of displaying competencies. Granted, the "mere possession of potentially valuable knowledge somewhere within an organization does not necessarily mean that other parts of the organization benefit from that knowledge" [31]. Knowledge sharing can therefore be interpreted as a highly desirable organizational and sectoral behaviour with a potential impact on both an organization's, and sector's survival and growth.

While a shared practice is the central element of a community of practice, they also form important social units. They can be seen as largely a construct with enough flexibility to incorporate a number of different individuals without forcing them give up their individuality. As Cohen [8] writes, "indeed, the gloss of commonality which it [the community] paints over its diverse components give each of them [individual members] an additional referent for their identities." The sense of identity evolves parallel to the feeling of membership and belonging towards a certain community of practice. This identity does not only foster knowledge sharing by focusing attention towards the group for problem solving. The strong social coherence further fulfils the need for affiliation when the organization fails to do so, and provide continuity in times of adversity [5].

\section{Knowledge Sharing and Learning}

Smaller organizations generally seek greater opportunities for social interactions, and have a higher likelihood for a sense of obligation to other members of a community of practice. A strong social coherence enables the creating and sharing of sector-specific knowledge [5]. This ability can be interpreted as a community's absorptive capacity for the acquisition or assimilation of new knowledge and its exploitation [9]. The exact patterns of an absorptive capacity depend on the context and the pre-existing stock of knowledge. Since they vary between organizations, the results are unique and extremely valuable for the organization.

In addition, boundary spanners link different communities of practice with each other and facilitate the emergence of even larger informal social network (see Ardichvili [1]). Boundary spanning refers to the act of extending across borders to build relationships to address complex problems. Boundary spanners - individuals who reach across boundaries - are therefore essential for avoiding the "fragmentation of the organization into silos of specialized knowledge and activity" [7]. 
Brown and Duguid [6] see a community of practice as a "privileged sites for a tight, effective loop of insight, problem identification, learning, and knowledge production". Practices evolve and are driven forward by learning. Within a community of practice, trust creates a safe environment for members to share challenges and explore new ideas, in addition to exchanging mere facts [23]. Adopting a social stance towards knowledge ensures a conceptual match between a community of practice and knowledge. Each organization provides a unique environment for processes of social learning and knowledge sharing within a community of practice. At core, the interaction with peers in other organizations, formally or informally, forges a community of practice that one can draw upon when looking for specific knowledge. The transformative nature of knowledge sharing and learning is therefore closely associated with professionalization of the organization and the NGO sector as whole. Consequently, the linkage between professionalization and a community of practice based on knowledge is such that the former transforms voluntary or social organisations into "formalized, knowledge intensive and professionally staffed organizations" [3]. The staff of NGOs, in particular their professional history, commitment to organizational goals, personal connections to the issue/s and other related aspects are thus contributory factors to an organization's professionalization [28].

\section{Knowledge Networks and Trust}

Members of a community of practice participate because the network provides a high value and reinforces trust amongst the community [24]. This can be disaggregated further by looking at the structural, relational, and cognitive dimensions.

The structural dimension describes "the overall pattern of connections between actors" [25].

A community of practice provides these distinct patterns of connections based on a shared practice. Becoming a member of a specific community of practice automatically links the new member to the other members of the network and vice versa $[4,5,22,29]$ thus enhancing its structural dimension.

The relational dimension refers to the personal relationships that members of the network have established with each other. Trust represents the core of this dimension. An arduous relationship between the parties involved represents an essential barrier to disseminating best practices within organizations [30]. A community of practice acts as a monitoring agency for maintaining trust. Members oversee each other's interactions and any act of untrustworthiness would be known fast within the community of practice, and in the process, potentially advancing the relational dimension.

Finally, the cognitive dimension comprises "those resources providing shared representations, interpretations, and systems of meaning among parties" [25]. A community of practice fosters shared beliefs and norms, enabled by the shared language developed within the community.

Suffice to say, community of practice analysis accepts the importance of networks and trust to understanding why people or organizations share or do not share. The willingness to share knowledge is based on trust between the sender and receiver; with the added caveat that individuals have to engage in "similar or shared practices to be able to share knowledge about those practices" [10]. Figure 1 shows the different dimensions of a community of practice with professionalization of the NGO sector as one important result. 


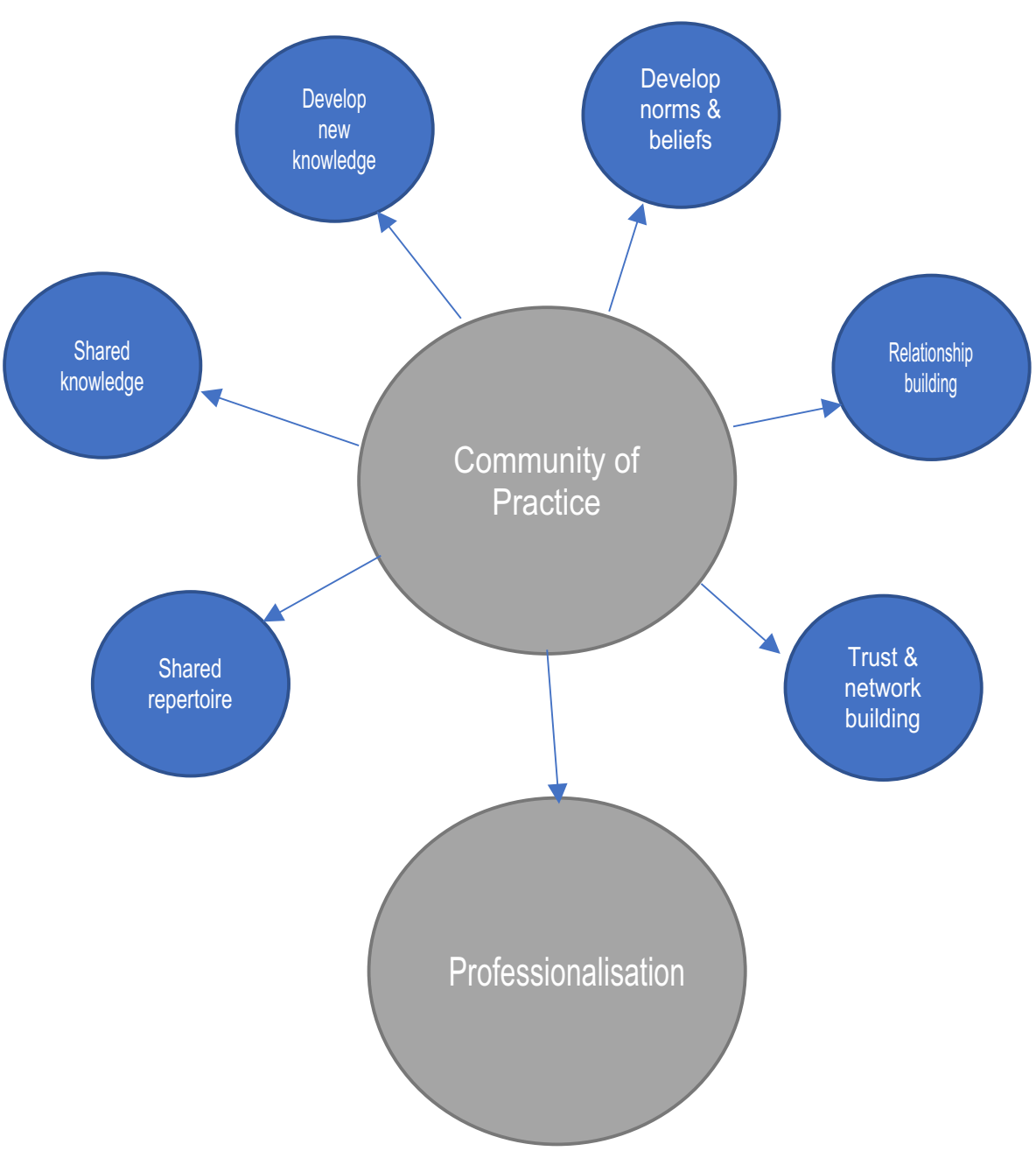

Fig. 1 Visualization of NGO's community of practice. (Source: Authors' own diagram)

\section{Methodology and Sample}

A total of 102 NGOs were surveyed (face-to-face) across four cities in China from 2013 to 2014: 19 were from Shanghai, 27 from Nanjing, 16 from Chongqing and 40 from Kunming (see Table 1). The survey probed into the organizational behaviour of NGOs in terms of ecology, engagement with other organizational actors, and the delivery of services.

NGOs were selected based on a snowballing technique. Moreover, only one respondent per NGO was elicited; we sought a response from the highest ranking member of the NGO. Although these parameters may lead to selection and/or gatekeeper bias, this was the most effective way to obtain information on the above topics particularly when many NGOs seek a low profile given the sensitive political context [2].

In line with the heterogeneity of the NGO sector in China, there is great variability in our sample in terms of location and scope of activities. In Kunming, environmental 
Table 1 Main organizational focus of surveyed NGOs ${ }^{\mathrm{a}}$ (percentage in parentheses)

\begin{tabular}{llllll}
\hline & Chongqing & Kunming & Nanjing & Shanghai & Total \\
\hline Welfare & $1(6.3)$ & $4(10.0)$ & $13(48.1)$ & $5(26.3)$ & $23(22.5)$ \\
Health & $2(12.5)$ & $15(37.5)$ & $1(3.7)$ & $3(15.8)$ & $21(20.5)$ \\
Environment & $4(25.0)$ & $10(25.0)$ & $3(11.1)$ & $2(10.5)$ & $19(18.6)$ \\
Education & $4(25.0)$ & $4(10.0)$ & $1(3.7)$ & $6(31.6)$ & $15(14.7)$ \\
Community development & $4(25.0)$ & $3(7.5)$ & $1(3.7)$ & $0(0.0)$ & $8(7.8)$ \\
NGO support & $0(0.0)$ & $0(0.0)$ & $4(14.8)$ & $1(5.3)$ & $5(4.9)$ \\
Cultural & $0(0.0)$ & $2(5.0)$ & $1(3.7)$ & $1(5.3)$ & $4(4.0)$ \\
Migrants & $1(6.3)$ & $0(0.0)$ & $2(7.4)$ & $1(5.3)$ & $4(4.0)$ \\
Gender & $0(0.0)$ & $2(5.0)$ & $0(0.0)$ & $0(0.0)$ & $2(2.0)$ \\
Legal support & $0(0.0)$ & $0(0.0)$ & $1(3.7)$ & $0(0.0)$ & $1(1.0)$ \\
Total & $\mathbf{1 6}$ & $\mathbf{4 0}$ & $\mathbf{2 7}$ & $\mathbf{1 9}$ & $\mathbf{1 0 2}$ \\
\hline
\end{tabular}

${ }^{a}$ While a NGO may engage in various issue areas, we categorize each NGO based on their stated main area of work

NGOs are more prevalent compared to the other three cities due to salient issues such as contention over the building of dams. The province of Yunnan (Kunming as its capital) has the highest density of environmental NGOs, and was the first province to allow foreign NGOs to enter, thus providing a backdrop for local NGOs to emerge with the support of their foreign counterparts. For Chongqing, the history of NGOs is much shorter and the types of NGOs much narrower. Nanjing and Shanghai have a robust social service delivery NGO sector. Shanghai is experimenting with various NGO services, from migrant children's education to elderly care. The activities of the social welfare sector with NGO participation is largely spearheaded by the Shanghai municipal and district authorities. Shanghai is one of the first large cities in China to undertake government contracting of social services on a large-scale. The focus on welfare delivery has, in part, shifted the orientation of NGOs in Shanghai. Over the last decade, Shanghai's NGOs have targeted community development rather than specific issues. With the latest trend in welfare contracting, NGOs in Shanghai are now focusing on working with the government to obtain contracts. Although the majority of the NGOs work in the broad area of service delivery we have further divided this category to be more specific: welfare, health, education and community development. Each of these four service delivery areas are equally broad, however, we have attempted to differentiate the type of work NGOs are engaged in. Under the category of welfare, NGOs may be engaged in the care of the elderly, orphans, disabled or poverty alleviation. The health category includes NGOs addressing HIV/AIDS and other disease or illness. Education includes those delivering education materials to rural villages, developing education curriculum, educating migrant children and other related activities. Community development includes organizations that work with local communities across different sub-groups and addressing intersecting issues such as community participation of the elderly.

The four case study cities were selected based on the assumption that the scope of organizational activities and development can be influenced by the local institutional 
environment. This is partially evident by the varying average organizational age of the NGOs across the four cities: 10.3 in Shanghai, 8.4 in Nanjing, 6.1 in Chongqing and 12.6 in Kunming (see Table 2). The four cities matter insofar as it tells us the type of NGOs that are prevalent, and relatedly the type of relationship they may have with state authorities and trust-building opportunities, all affecting the likelihood of a community of practice prospering.

\section{Findings}

\section{Staffing Profile}

As discussed in our theoretical background, the staffing profile of an organization, and the sector-at-large, is an important element to first consider when building up a community of practice. As Table 2 suggests, the number of full-time employees average 12.7 per NGO among the total sample, with 5.6 the least number of employees in Chongqing and 19.9 the most in Kunming. The number of part-time staff averaged 3.3 across the four cities, with 2.0 the lowest average in Nanjing and 4.6 the highest in Chongqing and Shanghai. With few permanent, full-time staff in our NGO sample, the possibility of fostering a long-lasting community of practice is difficult, and more acutely the case when factoring the staff member's years of work experience prior to joining the NGO - the average years of prior work experience was 3.3.

The responses from participants in our sample indicate that the majority had no prior NGO work experience before joining the organization (see Table 3). In addition, due to the relatively low wages in the Chinese NGO sector, there is generally a higher turnover relative to government and private enterprise sectors. Respondents in our sample reiterated time and again that low remuneration played a major determining factor in the lack of staff retention. One respondent working with people with disabilities aptly captures the sentiments expressed by many in relation to staff retention:

Most staff members leave because of low wages, and/or family reasons. Those that work in support of disabled people are mainly from other cities/area outside of Nanjing and often go home when their families desire them to go home.

Table 2 Average organizational age, staffing and experiences

\begin{tabular}{lllllll}
\hline & $\begin{array}{l}\text { Organizational } \\
\text { age (years) }\end{array}$ & $\begin{array}{l}\text { Permanent } \\
\text { staff \# }\end{array}$ & $\begin{array}{l}\text { Part- } \\
\text { time } \\
\text { staff \# }\end{array}$ & Volunteers \# & $\begin{array}{l}\text { Work } \\
\text { experience prior to } \\
\text { joining NGO } \\
\text { (years) }\end{array}$ & $\begin{array}{l}\text { Age of s } \\
\text { taff }\end{array}$ \\
\hline Shanghai & 10.3 & 8.0 & 4.6 & 11.7 & 2.2 & 31.5 \\
Nanjing & 8.4 & 17.3 & 2.0 & 443.4 & 3.5 & 32.2 \\
Chongqing & 6.1 & 5.6 & 4.6 & 3008.8 & 3.9 & 30.3 \\
Kunming & 12.6 & 19.9 & 2.1 & 7.2 & 3.5 & 36.9 \\
Overall Avg. & $\mathbf{9 . 4}$ & $\mathbf{1 2 . 7}$ & $\mathbf{1 3 . 3}$ & $\mathbf{8 6 7 . 8}$ & $\mathbf{3 . 3}$ & $\mathbf{3 2 . 7}$ \\
\hline
\end{tabular}


What this suggests is that the quality of any community of practice that emerges from Chinese NGOs will be initially weak, and quite possibly ineffectual given the lack of relevant work experience in the NGO world. As Roth [28] finds on her research on NGO professionalization and staffing globally, the personal and professional commitment of employees is important to the professionalization process. Since our sample points to high staff turnover, the commitment aspect to the organization - though not necessarily to the cause - will be a sticking point for individual NGOs as they seek to professionalize; particularly if employees move from NGOs to private or government sectors the knowledge gained may very well become dormant, forgotten or underutilized. In other words, the community's absorptive capacity for the acquisition and/or assimilation of knowledge and its usage in practice will be muted.

\section{Knowledge Absorption and Sharing}

Constructing a community of practice where knowledge sharing is the focal point of the community is immediately problematic in the context of China. Staffing challenges including staff retention and size of the NGO are problems for developing a coherent and sustainable community of practice. However, many of the NGOs indicated the importance of volunteers to satisfying staffing needs. Consequently, the large cohort of volunteers may serve as a burgeoning community of practice in the long-term, and one that develops a stronger sense of belonging to the community. The average number of volunteers varies quite dramatically in our sample size (see Table 2), in part due to the size of the organization and whether it is a grassroots NGO or a government-organized NGO (GONGO). In Chongqing, the average number of volunteers is $\sim 3009$, bearing in mind that six of the organizations are volunteer placement organizations. Nanjing had the next highest average number of volunteers of $\sim 443$, with many of the organizations working with groups such as the elderly and people with disabilities. Shanghai had an average of $\sim 12$ volunteers per NGO, and $\sim 7$ for Kunming. Given these vast differences, the potential for a community of practice to develop will vary city-to-city, as well as sub-sector to sub-sector (see e.g. [20] for a discussion on regional variations).

Following Ganesh and McAllum [13], we surmise, in the Chinese context, where there are high numbers of volunteers, the odds for increasing the absorptive capacity for the acquisition, assimilation and transmission of knowledge increases tremendously. As NGOs discuss recruitment strategies, many have noted that the hiring of paid staff members come mainly from the existing pool of volunteers. For example, the founder of Light of Hope, a Chongqing-based NGO working with migrants with more than 500

Table 3 Do existing permanent staff members have previous experience working with NGOs?

\begin{tabular}{llllll}
\hline & Yes & Some & No & N/A & Total responses \\
\hline Shanghai & $0(0.0 \%)$ & $8(42.1 \%)$ & $10(52.6 \%)$ & $1(5.3 \%)$ & 19 \\
Nanjing & $2(7.4 \%)$ & $10(37.0 \%)$ & $9(33.3 \%)$ & $6(22.2 \%)$ & 27 \\
Chongqing & $0(0.0 \%)$ & $8(50.0 \%)$ & $8(50.0 \%)$ & $0(0.0 \%)$ & 16 \\
Kunming & $25(62.5 \%)$ & $9(22.5 \%)$ & $4(10.0 \%)$ & $2(5.0 \%)$ & 40 \\
Total & $\mathbf{2 7 ( 2 6 . 5 \% )}$ & $\mathbf{3 5 ( 3 4 . 3 \% )}$ & $\mathbf{3 1 ( 3 0 . 4 \% )}$ & $\mathbf{9 ( 8 . 8 \% )}$ & \\
\hline
\end{tabular}


volunteers, noted that one of the main recruitment strategies include hiring university students, particularly those in social work, first as volunteers with an eye to developing them as future staff from the pool of volunteers. Non-Profit Incubator, operating in Nanjing's Yuhuatai District, shared a similar strategy of recruitment. According to the representative: "NPI tries to train the people it needs, moving recruits from volunteers to interns to full-time positions". Thus, in the long term, volunteers can potentially play an important element in facilitating the development of a community of practice. In cities like Chongqing and Nanjing where NGOs rely heavily on volunteers to fulfil project delivery goals, a community of practice will emerge informally given that the learning configuration will not be structured, notably when there are several hundreds of volunteers to manage.

\section{A Community of Experts}

Respondents in our sample indicated that Chinese NGOs lack the professionalism and expertise to be considered a community of experts that act as a coherent group in which they seek to inform and impact policy and policymakers. Just over half of those surveyed (51\%) believed Chinese NGOs are not part of an expert community. Chongqing is the only city where the overwhelming majority of respondents stated that NGOs cannot be considered as a community of experts $(68.8 \%)$, whereas the responses were split more evenly in Kunming (Yes: 45.0\%; No: 42.5\%). Qualitative responses qualified some of the sentiments. Two themes emerge from the responses. First, domestic NGOs have not obtained sufficient expertise in which they can be considered a community of experts. Second, the lack of professionalization, and established best/ worst practices, inhibits some development.

This sentiment was reiterated when discussing with NGO leaders and founders whether Chinese NGOs should be considered as a community of experts. In the case of Chongqing, those involved in NGOs that were newer and more highly reliant upon volunteers, thought of themselves as more novices, and reserve the "expert" designation for those that are older and more institutionalized, with the resources to afford expertise. As the Director of Chongqing Hemophilia Association, a health NGO, noted, most NGO leaders lack professional training and knowledge. Furthermore, when we consider the range of NGO leaders out there - for example, in the Chongqing Hemophilia Association's case the majority of staff are patients afflicted or have relatives living with illness - then it is difficult to consider these people as "qualified as experts". In such examples, those directly affected by the issue that the NGO seeks to remedy may not necessarily be considered as having high knowledge capital (see e.g. $[16,19])$. Yet, if we consider the flip side, these individuals will have established strong networks with other patients and thus, have the potential to mobilize supporters for advocacy. Findings from Chongqing suggest that the reliance on volunteers and for some organizations, relying on the lived experience of their staff (e.g. hemophilia), the building of a community of experts in line with professionalization goals may be challenged.

Finally, it is interesting to observe that a community of experts are associated with international NGOs, as a representative from Shanghai Sunrise suggested: "Some International NGOs in Shanghai are very professional and can be considered as a community of experts. But not for local NGOs". Similarly, Morning Tears, another 
Shanghai-based NGO, noted the same outlook: "Unlike International NGO, most of Chinese NGO are not professional and doesn't have many experts involved". Without this idea of community or established expertise, it is difficult to envisage a formal structure, a professional association withstanding, to facilitate the establishment of a community of practice. Furthermore, smaller organizations were more inclined to see their role not as a community of experts but as "doers", as this one representative from Kunming noted: "We are the doers, not the so-called experts...".

\section{Knowledge Networks and Trust}

As discussed earlier, looking at the structural, relational, and cognitive dimensions to a community of practice, trust, familiarity and mutual understanding are prerequisites to successfully transfer tacit and/or overt knowledge. All of these characteristics are also affected by the interactional dynamics and knowledge background, between and within participants. For instance, the reliance on volunteers, particularly in Chongqing and Nanjing, suggest that the interactional dynamics for a community of practice will be informal. This is evident when the Director of the Chongqing Youth Education Volunteer Association - a large youth-based NGO with more than 3000 volunteers remarked that of the 11 permanent staff, four or five of the employees had previous experience in working with the NGO as volunteers. In these situations, the stress of managing a large cohort of volunteers, with so few staff, demonstrate the challenges in formally structuring a community of practice. Nonetheless, the trusting bond, and shared sense of belonging to the larger NGO sector, established prior to becoming a permanent staff member was the first step in creating a capital that can expedite shared learning and practices. Similar to what Nistor and Fischer [26] found in the context of academia, in a community of practice, knowledge is expressed and applied through participation.

Our sample does present some pessimism in this regard. When we queried, "do existing permanent staff members have previous experience working with NGOs?" $34.3 \%$ of the total responded that existing staff have had "some" previous experience and $30.4 \%$ having no previous experiences at all (see Table 2). For the former response, this will vary widely in terms of years of experience as well as type of experience, for example, working as a volunteer or paid employment in an NGO. Nevertheless, as we have suggested, the increasing reliance on volunteers to carry out program goals will suggest a reverse of this trend in the long run. This is notably the case if volunteers, who are increasing their knowledge networks over time, remain or return to the NGO sector.

\section{Discussion}

\section{A Volunteer-Driven Community of Practice?}

Admittedly, the large presence of volunteers in Chinese NGOs, on its own, may be counter-intuitive to establishing and fostering the classic community of practice. Received wisdom suggest that sectors which are prone to outsourcing, sporadic or freelance work are less effective at supporting a community of practice than stable work 
groups or vertically integrated bureaucracies. Nevertheless, when observing the recruitment strategies for volunteers in the sample cities, we were open to rethinking this notion. Time and again we noticed that the recruitment of new volunteers was often predicated on the suggestions of existing volunteers. Further, for many of the NGOs in our sample, exemplified by Shanghai's Home Sweet Home, working in community development, new staff members were recruited from the existing pool of volunteers, suggesting at minimum, the seeds of a burgeoning community of practice, and a sense of identity and belonging to the community-at-large. In another example, officials at Nanjing's Ha Lei House, articulated employees who eventually become staff follow a similar process: "Right now recruitment is through the professional school; first students become volunteers, and then they become part-time staff, and then some people will become full-time staff'. Consequently, we can anticipate that a volunteerdriven community of practice is emerging in parts of China and it will play an important role in the post-Charity Law regime. This is more acutely the case given the Social Credit System scheduled to come online in 2020 will most likely reward individuals for volunteering work in the community.

Granted, we must entertain the notion that networks of volunteers can be a hindrance to NGOs' programming and meta-goals. According to a health focused NGO working with cancer patients, Xiao Xia, the founder observed that older volunteers "don't have the energy and the education level to be able to take on tasks like managing websites. University volunteers don't stay long enough, and they don't know the work and the clients very well". Thus, the different capacities of the volunteers may work against the NGO in building a volunteer-based community of practice, since neither the older nor university-aged volunteers appear to be capitalizing on their shared experience to facilitate the work of the NGO. Furthermore, the varying levels of skills sets and experience among volunteers may potentially lead to an uneven development of community of practice, and possibly a very weak community of practice.

\section{Knowledge Capital, Networking and Boundary Spanning}

We suggest that a community of practice will foster the development of network capital among Chinese NGOs and increase their willingness to share knowledge. To wit, NGO representatives indicated that the network of volunteers is useful for individual volunteers in establishing and improving one's network capital. Notably as NGOs seek to hire permanent staff, representatives indicated that drawing on from the existing pool of volunteers is standard practice. As Green Stone, a Nanjing-based environmental NGO pointed out, the age of the volunteers is directly equated with not only the volunteer's knowledge and network capital, but that of the organization: "the major problem is that members are fairly young, so they lack experience and they lack capital; they don't know as many people and don't have much resource. Also, Green Stone, in truth, is still an immature organization, there was a major shift of goal in 2006, and there were no activities in a few years, so the organization really lacks experience". The organization's individual-level knowledge and network capital, and maturity/experience are thus inextricably linked in the eyes of this NGO representative. It is also interesting that four of the Shanghai NGOs cited one of the main reasons for staff departure, aside from low pay, is the desire to pursue further education. Furthermore, given the marketization of the Chinese NGO sector, the working culture of Chinese NGOs is changing. As 
Zhao [34] notes in her research, the "wolf-spirit" (langxing) or entrepreneurial spirit widely embraced by Chinese NGOs have placed female NGO workers and their "'noncommercial' experiences in a more marginalized position". And this is clearly, echoed in the reasons given by our respondents regarding staff departures: "Especially for young women who are getting married and preparing to have children, family members might not want them to continue working in this NGO..." Thus, departure of female staff is another factor that contributes to the slow growth of the community of practice in the Chinese NGO sector.

In this backdrop, knowledge and network capital are therefore important mechanisms to facilitate the growth of an organization, starting from the capital of individual members, whether volunteer or staff. In turn, this capital will develop and grow a community of practice in the long-term, rather than a community of practice fostering the knowledge capital. The sector is also an important determinant for respondent's perception of whether NGOs should be consider of community of experts. A Nanjing representative working in autism believed: "There is still a lack of expertise in the area of serving children with autism yet, there is no standard." In the case of autism, this respondent felt that there is no prior history of dealing with autism, perhaps both at the state and societal level, it would be difficult to assess these NGOs as community of experts. Of course, knowledge capital will be gained once the community of practice matures (see e.g. Hsu and Hasmath [19]), but the knowledge capital of individual NGO members is a prerequisite for the growth of that community. Yet, in the context of Green Stone, we suggest that the immaturity of the organization and youth of the organization's volunteers, could both be potential factors in hindering the development of the NGO, insofar as, the weakness of the community of practice maybe an insufficient resource to draw upon and thus relying on volunteers to support the organization's work may be ineffectual. Nonetheless, as Fulda and Hsu [11] note there are three other forms of capital in which an NGO can draw upon, aside from their social capital (i.e. networks), they include, cultural, economic and symbolic.

We also suggest that boundary spanners, linking different communities of practice with each other, will play a greater role in the maturation of each sector's community of practice in the future. We already see this in the case of Shanghai's Walking into Life and Learn, working to educate disadvantaged children. This NGO has leveraged the founder's network outside of the NGOs sector, to gain knowledge about best and worst practices, as well as to aid in organizational needs from recruiting staff to financing the organization. Likewise, another Shanghai NGO working with disadvantaged children, Morning Tears, has capitalized on the founder's previous position in the local government to help access financial resources and expertise needed for their children's work.

\section{The Changing Institutional Environment}

The authoritarian, corporatist institutional environment that Chinese NGOs operate in suggests that disjunctive changes can serve as a catalyst for the (re-)development of a community of practice. Namely, due to regulatory changes such as the 2016 Charity Law, NGOs are pressured to adapt to or to accommodate change, or else be made redundant. This institutional pressure - the organizational will to survive (see e.g. [32]) - suggests that a formal or informal community of practice will emerge for NGOs to share knowledge for survival purposes and also, in response to the Party-state's push 
for greater involvement of NGOs in the delivery of social services domestically and internationally.

For NGOs, learning from each other will be both endogenously (with respect to best/ worst practices disseminated and shared as embedded evolution of practices) and exogenously sourced (in response to new technologies or challenges like shifts in demand-side expectations or budgetary constraints). With economic and political challenges impacting the survival and development of Chinese NGOs, we can expect these organizations to become much more creative in drawing on their four forms of capital (economic, social, cultural and symbolic) not only for self-preservation [12] but perhaps to the extent in creating a community of practice as a support mechanism. In seeking to adapt to endogenous and exogenous changes, and paired with the desire to secure government contracts as a way to ensure funding for the NGO (see e.g. [14]), a community of practice is likely to appear as a way of institutionalizing the trials and errors of adaptation. While this remains in the realm of conjecture at this stage, especially given the relative infancy of the professionalization of the sector, we suggest that this is the most plausible direction given the informal networks that have arisen from the large volunteer base among the NGOs surveyed.

\section{Conclusion}

Our study illustrates there is an inherent and polarizing tension when it comes to discerning whether a community of practice will emerge in the NGO sector in China. On one side, when the majority of NGOs in our sample do not see themselves as part of a community of experts, it presents a huge challenge for the possibility of a structured and institutionalized community of practice. On the other side, in order to survive and prosper in the post-Charity Law regime, NGOs must quickly learn how to adapt. They must learn past lessons and implement best practices and avoid worst ones, to survive in this new institutional environment. This, we suggest, is best accomplished by developing a community of practice to share knowledge with other NGOs. Our research contributes to the literature on the professionalization of NGOs in the context of China by understanding and analyzing why people or organizations share or do not share. We theorize the level of professionalization required, in order to construct a community of experts. By considering the different aspects of a COP, we have teased out the essential dimensions of such a community and assessed our empirical material within such a framework.

One of the main limitations of our research is the snowballing technique used to selection our NGOs. We acknowledge that such methodology can lead to selection or gatekeeper bias. However, given the sensitive political context, and even more so postCOVID-19, this was the most effective way to obtain information.

Looking ahead, there are key normative isomorphic pressures that will push for the development of community of practice [16]. Namely, increased employee transfers from one NGO to another, or utilizing volunteers who have previous NGO experiences will increase knowledge sharing and the ability to foster a mature community of practice. Further, the NGO founder's or leader's knowledge network - and relatedly, their ability to engage in boundary spanning, to learn about other sectors survival strategies - will be a mechanism to develop a mature community of practice. 
Finally, it is not coincidental that the state has signal through Article 24 of the Charity Law that a professional association is encouraged to share best/worst practices, and in turn, forge a mature community of practice. The state, in present-day and in the future, wants Chinese NGOs' activities to be predictable in order to engineer greater trust of the NGO sector, as well as to increase greater odds of soliciting funding from outside sources. In short, it is in the interest of Chinese NGOs to form a mature community of practice - their long-term survival depends on it.

Acknowledgements The authors are grateful for feedback received on earlier versions of this paper presented at the Center on Philanthropy and Civil Society, Stanford University, the 2015 Association for Research on Nonprofit Organizations and Voluntary Action Annual Conference (Chicago, USA), and the 2016 International Society for Third Sector Research Conference (Stockholm, Sweden). This research is supported by the Social Sciences and Humanities Research Council of Canada.

\section{References}

1. Andreassen, T.A., E. Breit, and S. Legard. 2014. The making of 'professional amateurs: Professionalizing the voluntary work of service user representatives. Acta Sociologica 57 (4): 325-340.

2. Ardichvili, A. 2013. Learning and knowledge sharing in virtual communities of practice: Motivators, barriers, and enablers. Advances in Developing Human Resources 10 (4): 541-554.

3. Atkinson, R., and J. Flint. 2001. Accessing hidden and hard-to-reach populations: Snowball research strategies. Social Research Update 33: 1-5.

4. Borzillo, S., S. Aznar, and A. Schmitt. 2011. A journey through communities of practice and why members move from the periphery to the core. European Management Journal 29: 25-42.

5. Breu, K., and C. Hemingway. 2002. Collaborative processes and knowledge creation in communities of practice. Creativity and Innovation Management 11 (3): 147-153.

6. Brown, J.S., and P. Duguid. 2001. Knowledge and organization: A social-practice perspective. Organization Science 12 (2): 198-213.

7. Casciaro, T., and M.S. Lobo. 2005. Competent jerks, lovable fools, and the formation of social networks. Harvard Business Review 83 (6): 92-99.

8. Cohen, A.P. 1985. The symbolic construction of community. London: Routledge.

9. Cohen, W.M., and D.A. Levinthal. 1990. Absorptive capacity: A new perspective on learning and innovation. Administrative Science Quarterly 35 (1): 128-152.

10. Duguid, P. 2005. 'The art of knowing': Social and tacit dimensions of knowledge and the limits of the community of practice. The Information Society 21 (2): 109-118.

11. Freidson, E. 1984. The changing nature of professional control. Annual Review of Sociology 10: 1-20.

12. Fulda, A., and J.Y.J. Hsu. 2019. The resource mobilization cycle: How Chinese CSOs leverage cultural, economic, symbolic and social capital. China: An International Journal.

13. Ganesh, S., and K. McAllum. 2012. Volunteering and professionalization: Trends in tension? Management Communication Quarterly 26 (1): 152-158.

14. Hasmath, R., and J.Y.J. Hsu. 2008. NGOs in China: Issues of good governance and accountability. Asia Pacific Journal of Public Administration 30 (1): 1-11.

15. Hasmath, R., and J.Y.J. Hsu. 2014. Isomorphic pressures, epistemic communities and state-NGO interactions. The China Quarterly 220: 936-954.

16. Hasmath, R., and J.Y.J. Hsu. 2016. NGO governance and management in China. New York: Routledge.

17. Hasmath, R., T. Hildebrandt, and J.Y.J. Hsu. 2019. Conceptualizing government-organized non-governmental organizations. Journal of Civil Society 15 (3): 267-284.

18. Hsu, J.Y.J., and R. Hasmath. 2014. The local corporatist state and NGO relations in China. Journal of Contemporary China 23 (87): 516-534.

19. Hsu, J.Y.J., and R. Hasmath. 2017. A maturing civil society in China? The role of knowledge and professionalization in the development of NGOs. China Information 31 (1): 22-42. 
20. Hsu, J.Y.J., C. Hsu, and R. Hasmath. 2017. NGO strategies in an authoritarian context, and their implications for citizenship: The case of the People's Republic of China. Voluntas: International Journal of Voluntary and Nonprofit Organizations 28 (3): 1157-1179.

21. Kaser, P.A.W., and R.E. Miles. 2002. Understanding knowledge activist's successes and failures. Long Range Planning 35: 9-28.

22. Kerno, S.J. 2008. Limitations of communities of practice: A consideration of unresolved issues and difficulties in the approach. Journal of Leadership and Organizational Studies 15 (1): 69-78.

23. Lesser, E.L., and J. Storck. 2001. Communities of practice and organizational performance. IBM Systems Journal 40 (4): 831-841.

24. McDermott, R. 2000. Knowing in community: 10 critical success factors in building communities of practice. IHRIM Journal 4: 19-26.

25. Nahapiet, J., and S. Ghoshal. 1998. Social capital, intellectual capital, and the organizational advantage. The Academy of Management Review 23 (2): 242-266.

26. Nistor, N., and F. Fischer. 2012. Communities of practice in academia: Testing a quantitative model. Learning, Culture and Social Interaction 1: 114-126.

27. Probst, G., and S. Borzillo. 2008. Why communities of practice succeed and why they fail. European Management Journal 26: 335-347.

28. Roth, S. 2016. Professionalisation and precariousness: Perspectives on the sustainability of activism in everyday life. Interface: A Journal for and About Social Movements 8 (2): 29-58.

29. Sharkie, R. 2005. Precariousness under the new psychological contract: The effect on trust and the willingness to converse and share knowledge. Knowledge Management Research and Practice 3: 37-44.

30. Szulanski, G. 1996. Exploring internal stickiness: Impediments to the transfer of best practice within the firm. Strategic Management Journal 17: 27-43.

31. Szulanski, G. 2000. The process of knowledge transfer: A diachronic analysis of stickiness. Organizational Behavior and Human Decision Processes 82 (1): 9-27.

32. Tam, J., and R. Hasmath. 2015. Navigating uncertainty: The survival strategies of religious NGOs in China. Journal of Civil Society 11 (3): 283-299.

33. Wenger, E. 1998. Communities of practice: Learning, meaning, and identity. New York: Cambridge University Press.

34. Zhao, H. 2020. The politics of doing gongyi: An ethnographic study of Chinese NGOs. PhD Thesis, University of East Anglia, Norwich, England.

Reza Hasmath (Ph.D., Cambridge) is a Professor in Political Science at the University of Alberta. He has previously held faculty positions in management, sociology and political science at the Universities of Toronto, Melbourne and Oxford, and has worked for think-tanks, consultancies, development agencies, and NGOs in USA, Canada, Australia, UK and China. His award-winning research looks at evolving state-society relationships in authoritarian contexts, with an emphasis on China and NGO activities.

Jennifer Y. J. Hsu (Ph.D., Cambridge) is a Visiting Fellow in the Social Policy Research Centre at the University of New South Wales. Jennifer's research is primarily focused on relations between state and nongovernmental organisations (NGOs) in China, particularly the scope of interactions between the local state and NGOs. Within this research program, she has sought to locate her research in several interdisciplinary domains: theories of state-society relations, organisational development of NGOs and civil society, and the internationalisation of Chinese NGOs. The different areas of her research enhance our theoretical understanding of how state and society engage under varying socio-political environments. Her monograph: State of Exchange: Migrant NGOs and the Chinese Government details the importance of the local state in NGO development. 